\title{
Study on the aging characteristics of silicone rubber materials for composite insulators
}

\author{
Pengkang Xie*, Kai Ning \\ State Key Laboratory of Disaster Prevention \& Reduction for Power GridTransmission \& Distribution Equipment, Changsha 410007 \\ China.
}

\begin{abstract}
The electron beam radiation method is emitted by electronic accelerators, which can change the chemical physical properties of radiation. Silicone rubber samples after different irradiation intesities were carried out for the $1000 \mathrm{~h}$ aging test, and the electronic scanning microscopy (SEM), mechanical tensile and hydrophhy angle of the silicone rubber sample were measured, the test results shows that: after 1000h aging test, the visual apperence of the sample did not changed, the SEM showed that the surface of the silicone rubber became rough and the porosity increased, and the mechanic tension decrease. For moderate Irradiation intensity $(60 \mathrm{KGy})$, the aging characteristics of silicon rubber can be improved.
\end{abstract}

\section{Introduction}

Composite insulator is mainly composed of composite silicone rubber umbrella skirt, epoxy resin core rod and other materials[1-3]. Compared with traditional porcelain and glass insulators, composite insulators have a series of advantages such as light weight, good insulation and anti-pollution performance, so they are widely used in power electric systems. Silicone rubber composite insulator made by high temperature vulcanization is the main material of external insulation of conposite insulator, during the long-term outdoor operation, degradation of mechanical and electrical performance of silicon rubber will shorten the service life of composite insulator, which may even cause flashover of transmission lines. Therefore, in order to improve the economical efficiency, reliability and stability of transmission lines, it is necessary to carry out research on anti-aging technology of silicone rubber.

From the microscopic point of view, in the process of preparing silicone rubber molecules, the chain structure is cross-linked to form a three-dimensional network structure. The silicone rubber for composite insulators is formed by mixing polyorganosiloxane with a variety of chemical additives by heating vulcanization. Due to the uneven dispersion of cross-linking agent in the adhesive during the mechanical mixed curing reaction, the crosslinking degree of surface and internal chemical reaction differ widely, resulting in poor physical properties of silicon rubber and the phenomenon of aging failure is easy to occur in the field use.

The electron beam radiation method irradiates the irradiated material by the electron beam emitted by the electron accelerator, which can change the chemical and physical properties of the irradiated material[4-7]. At present, the method of electronic irradiation modification has been widely used in cable processing, food disinfection and other fields. However, there is no relevant report on the research of improving the service life of silicone rubber by electronic irradiation [8-10].

Based on the above status, different doses of electron irradiation were carried out for the silicone rubber samples formed by thermal aging in this paper, and $1000 \mathrm{~h}$ accelerated aging test was carried out for the silicone rubber samples before and after irradiation. Electron tunnel scanning mirror (SEM), mechanical tensile force and hydrophobicity of the silicone rubber samples before and after the test were compared. On the basis of the experimental data, the mechanism of the anti-aging performance of electron irradiation was analyzed, and the optimal anti-aging dose was obtained. The study in this paper provides a new way to improve the anti-aging performance of silicone rubber.

\section{Electron irradiation and aging test of silicone rubber}

\subsection{Test specimen}

The silicone rubber material, which was traditionally vulcanized by heating, was cut into a $2 \mathrm{~mm}$ thickness and $20 \mathrm{~cm} * 10 \mathrm{~cm}$ width flake form (Fig. 1). The material was placed in the Place on radiation production line and the electron irradiation dose of $60 \mathrm{KGy}$ and $100 \mathrm{KGy}$ was applied to the sample(Fig. 2).

The silicone rubber samples were washed by deionized water ultrasonic for $30 \mathrm{~min}$ and then placed in the aging box (Fig.3). The silicone rubber aging test was conducted for 1000 hours.

* Corresponding author: xiepengkang@126.com 


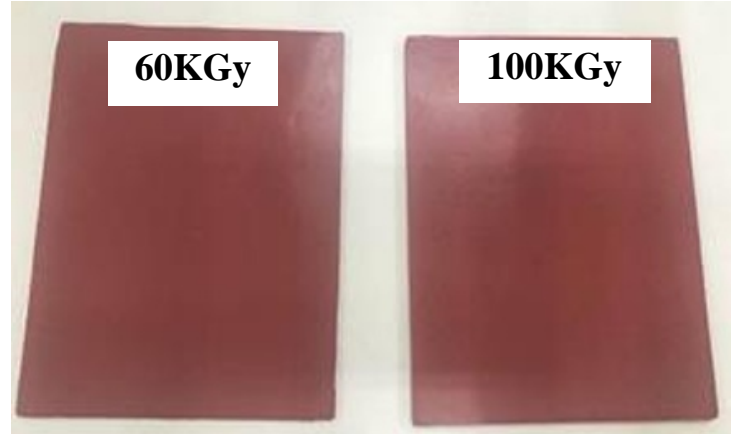

Fig. 1. silicone rubber sample after electron irradiation

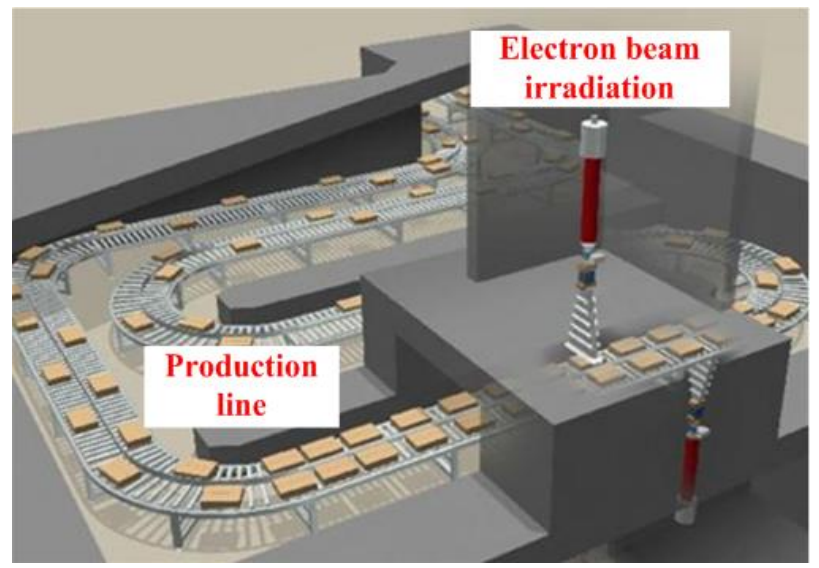

Fig. 2. silicone rubber sample after electron irradiation

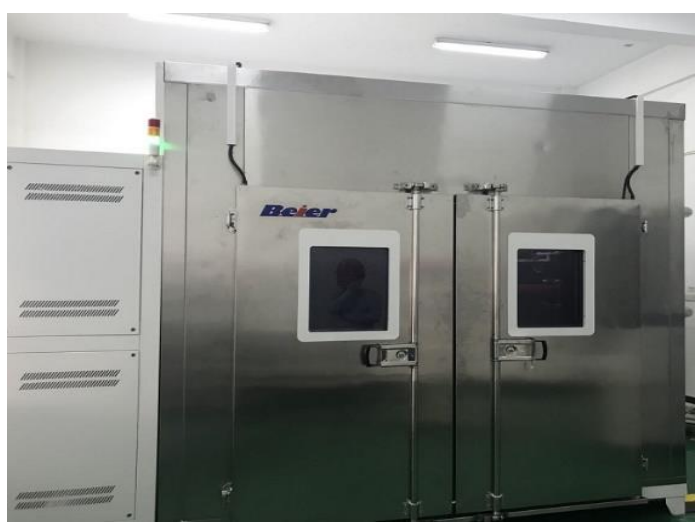

(a) Outside view

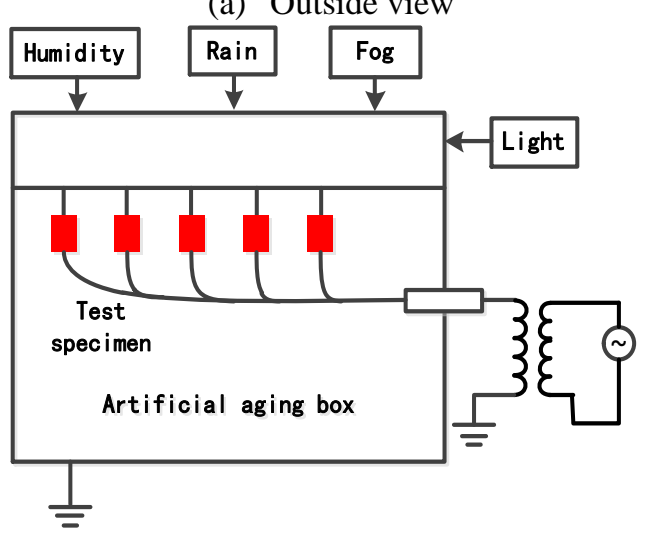

(b) Schematic diagram

Fig.3. Artificial climatic aging test chamber

Humidity of the climate aging box was maintained at $95 \%$, the temperature is $50^{\circ} \mathrm{C}$. The solar radiation intensity is $550 \mathrm{~W} / \mathrm{m}^{2}$. After aging test, the samples were taken out, cleaned and dried, and mechanical tensile force, SEM, hydrophobicity were tested.

\subsection{Test method}

Surface inspection. After cleaning the silicone rubber skirt, observe its appearance roughness. At the same time, the microstructure of the surface and cross section was observed under electron tunneling microscope.

Mechanical tension test. The dumbbell shape with shear growth degree of $25 \mathrm{~mm}$ and width of $6 \mathrm{~mm}$ was used to conduct tensile test of silicone rubber according to Chinese national standard GBT528-2009, and the tensile force of silicone rubber sheets with different irradiation intensity before and after aging was measured.

Hydrophobicity test. 3 samples were taken for hydrophobicity test, and the contact Angle of water droplets before and after aging of silicone rubber was measured by instrument, referring to IEC/TS 62073003.In the test, if the static contact Angle is greater than $90^{\circ}$, the composite silicone rubber is considered to have hydrophobicity, on the contrary, it is not considered to have hydrophobicity.

After aging test, the samples were taken out, cleaned and dried, and mechanical tensile force, SEM, hydrophobicity and other parameters of the silicone rubber material were tested.

\section{Test results}

\subsection{Appearance change}

The micrographs of silicone rubber materials with different radiation intensity before and after aging were observed by optical microscope, as shown in Fig. 3 and Fig. 4.
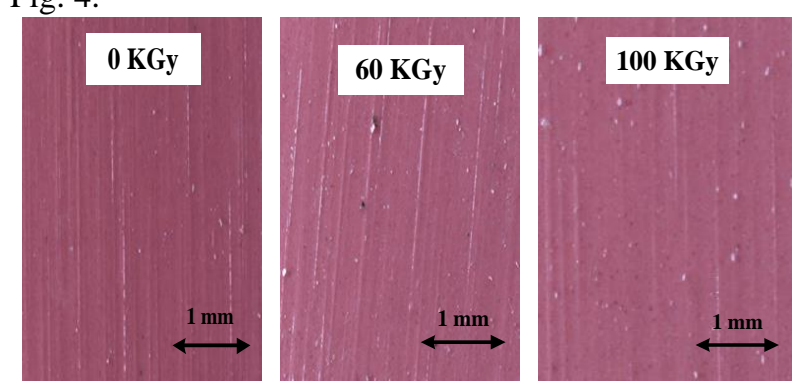

(a) before aging test observed by optical microscope
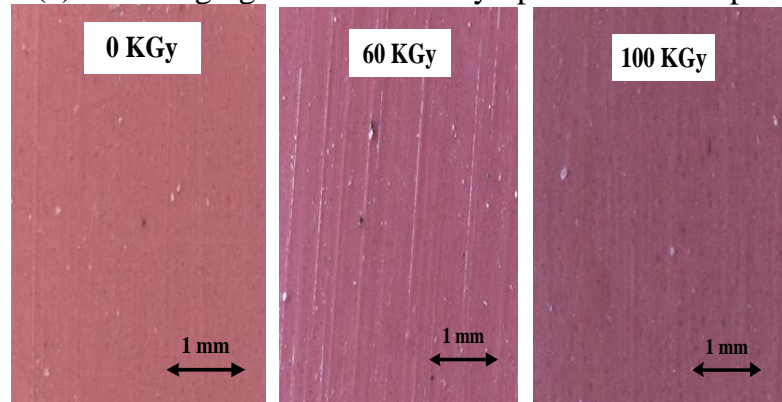

(b) after aging test observed by optical microscope Fig.4 Micrographs of silicone rubber materials before and after $1000 \mathrm{~h}$ aging test observed by optical microscope 
From the perspective of optical electron microscopy, the surface structure of silicone rubber changed little after $1000 \mathrm{~h}$ of aging. In order to study the changes of microstructures on the surface of silicone rubber after environmental aging, scanning electron microscopy (SEM) was used to observe the surface microstructure of silicone rubber before and after aging, as shown in Fig. 5.

From SEM picture in Fig.4, the surface porosity of silicon rubber surface porosity increased after aging. As the irradiation dose increases, the porosity of the silicone rubber increases, from which it can be indicated that, electron irradiation can relieve the climate aging characteristics of silicone rubber when irradiation dose is $60 \mathrm{KGy}$. As irradiation dose continues to increase, the porosity of silicon rubber re-increases.

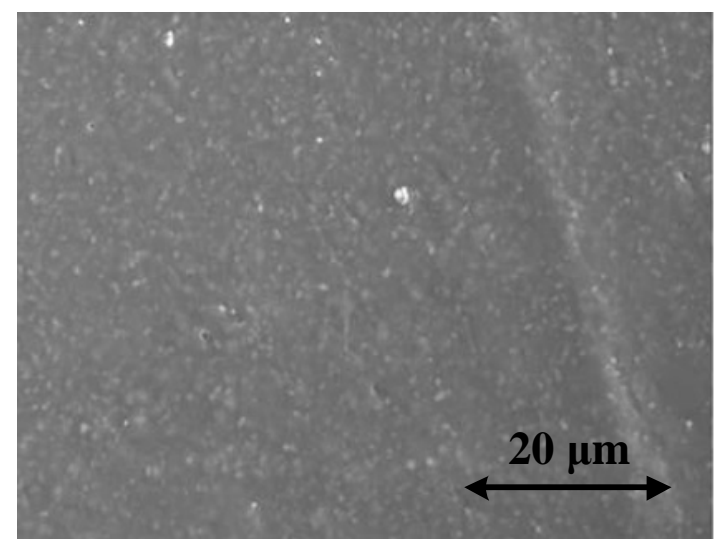

(a)ungaged

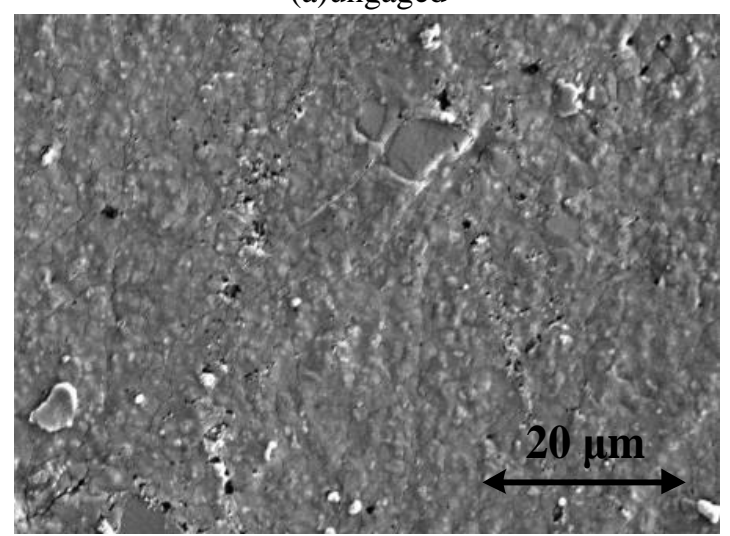

(b)after $1000 \mathrm{~h}$ aging, $0 \mathrm{KGy}$

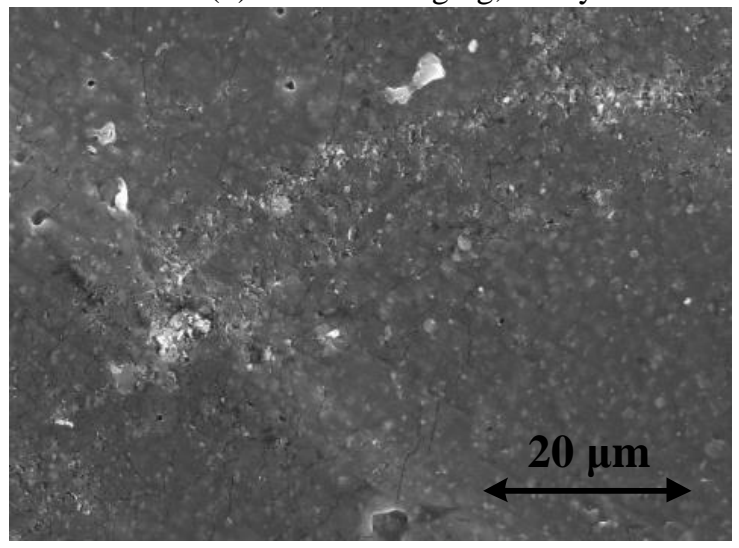

(c)after 1000h aging, 60Kgy

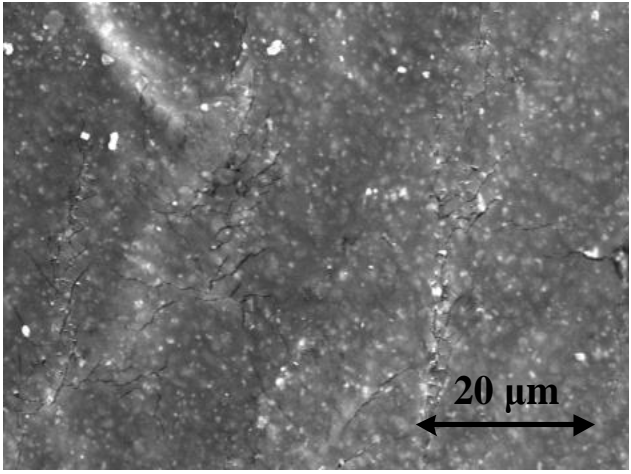

(d)after 1000h aging, $100 \mathrm{KGy}$

Fig.4 SEM graph of different species after $1000 \mathrm{~h}$ aging test

\subsection{Mechanical tension detection}

The results of the tensile test results were compared with the different irradiation intensity, as shown in table 1 and Fig.5. According to the experimental results, the stress changes were the minimum and the stress of the mechanical resistance was the most strong.

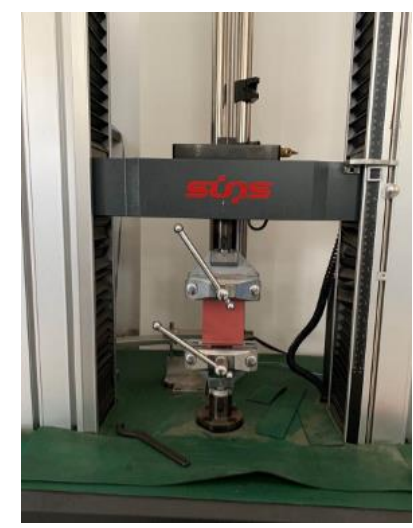

Fig.5. Silicone rubber tensile test

Table 1. The stress of silicone rubber before and after aging

\begin{tabular}{|c|c|c|}
\hline & Before aging & After aging \\
\hline $0 \mathrm{KGy}$ & $510 \mathrm{kN}$ & $484 \mathrm{kN}$ \\
\hline $60 \mathrm{KGy}$ & $595 \mathrm{kN}$ & $538 \mathrm{kN}$ \\
\hline $100 \mathrm{KGy}$ & $580 \mathrm{kN}$ & $525 \mathrm{kN}$ \\
\hline
\end{tabular}

\subsection{Appearance change}

Hydrophobic angle of diffenent test species were measured (average value of 20 species under each condition). The test results are shown in Fig.5 and Table.2.

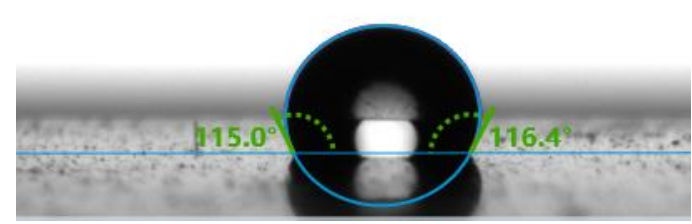

(a)unaged, 0KGy 


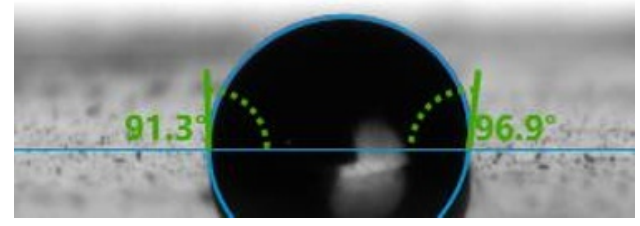

(b)unaged, 60KGy

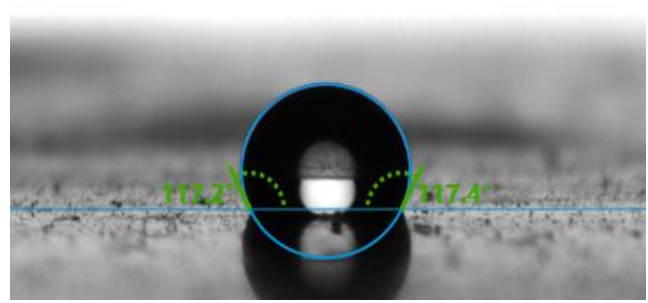

(c)unaged, 100KGy

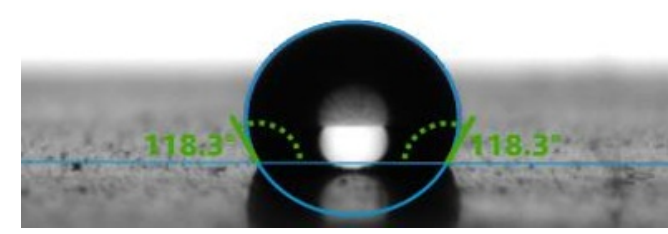

(d)1000h aged, 0KGy

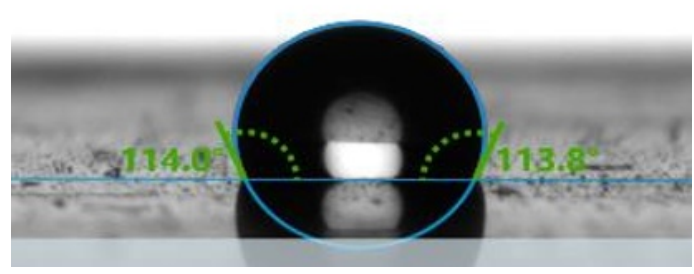

(e)1000h aged, 60KGy

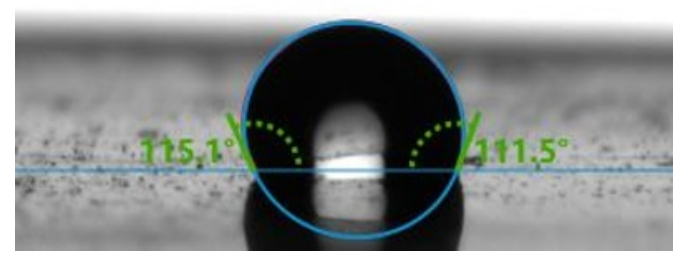

(f) $1000 \mathrm{~h}$ aged, $100 \mathrm{KGy}$

Fig.6. Hydrophobic angle of diffenent test species

Table 2. Hydrophobic angle of silicone rubber before and after aging

\begin{tabular}{|c|c|c|}
\hline & Before aging & After aging \\
\hline $0 \mathrm{KGy}$ & $115.39^{\circ}$ & $112.46^{\circ}$ \\
\hline $60 \mathrm{KGy}$ & $116.11^{\circ}$ & $112.82^{\circ}$ \\
\hline $100 \mathrm{KGy}$ & $115.91^{\circ}$ & $110.47^{\circ}$ \\
\hline
\end{tabular}

Before aging, with the increase of irradiation dose, hydrophobic angle increases first and then decrease.
After aging test. Hydrophobic angle of eah species decreases. As the irradiation intensity increases, the hydrophobic first increases and then increases. From which it can be indicated that, moderate irradiation intensity can increase the mechanic and electric characterstics of silicon rubber.

\section{Conclusion}

This paper studies the influence of irradiation intensity on the electric and mechanic characteristics of silicon rubber. According to the test results, following conclusions can be made:

1. After $1000 \mathrm{~h}$ aging test, the visual appearance of the sample did not change. SEM shows that the surface of silicone rubber became rough after aging and the porosity increased.

2.As the irradiation intensity increases, the mechanical tension and hydrophobic angle of silicon rubbber increases firstly and then decreases.

3. Moderate irradiation intensity can effectively inprove the aging characteristics of silicon rubber.

This work is supported by Changsha Science and Technology project in Hunan Province (kq 1804051), and Science and Technology project of State Grid Corporation of China ( 5216A01600W3,5216A01800JG)

\section{References}

1 F. Napolitano, IEEE Trans. Electromagn. Compat., 53, 108, (2011).

2 Y. Zhang, Q. Yang, S. Xie and C. Zhang, IEEE T. Electromagn. C., 6, 1 (2019).

3 X. Jiang, S. Fan, Z. Zhang, C. Sun and L. Shu, IEEE T. Dielect. El. In., 25,. 919, (2010).

4 S. Visacro, C.R. de Mesquita, R.N. Dias, F.H. Silveira and A. De Conti, IEEE T. Electromagn. C., 54, 1028, (2012).

5 W. Sima, D. Luo, T. Yuan, S. Liu, P. Sun and T. Li, IEEE T. Power Deliver., 33, 2125, (2018).

6 F.H. SilveiraS. Visacro and A. De Conti, IEEE T. Electromagn. C., 55, 1195 (2013.).

7 W. Sima, D. Luo, T. Yuan, S. Liu, P. Sun and T. Li, IEEE T. Power Deliver., 33, 2125 (2018).

8 P. N. Mikropoulos and T. E. Tsovilis, IEEE Trans. Dielectr. Electr. Insul., 20, 202 (2013).

9 A. Borghetti, C. A. Nucci, and M. Paolone, IEEE Trans. PowerDeliv., 22, 684, (2007)

10 P. N. Mikropoulos and T. E. Tsovilis, IEEE Trans. Dielectr. Electr. Insul., 20,. 202, (2013). 